A review of Dr Bagnall's 'Thysanoptera collections by L. A. Mound of the British Museum (Natural History) has just appeared (Bulletin of the British Museum (Natural History) Entomology, suppl. 2; 1968). In 1932 the museum purchased Dr Bagnall's collection, which at that time consisted of about 17,000 specimens of which 430 were type specimens and 750 paratypes. Sipecimens were added to the collection by Dr Bagnall until his death, and now his collections, together with the other material in the museum, contain about 10,000 slides of more than 1,200 recognized species, in addition to unworked species.

Many of Bagnall's nominal species have never been re-examined since they were first described. It has been found that some of his original descriptions are inaccurate in some respects, and Mr Mound has therefore included in his review 134 new generic and specific synonymies and 39 new combinations. The original descriptions have been compared in each case with the material remaining in Dr Bagnall's collection, lectotypes have been selected for many species and the original host and particulars of locality have been given for each species. Of the forms described by Bagnall 66 generic and 383 specific names are accepted by $\mathrm{Mr}$ Mound. Mr Mound has also included a biographical note on Dr Bagnall and a general account of the history of his collections with a list of the missing species and a list of the species ascribed to Bagnall in error.

In 1929 when Bagnall was presented with the honorary degree of DSe from the University of Durham, the university journal referred to him as "the best entomological field worker in the country and one of the world's authorities on thrips". Mr Mound describes him as an "excellent naturalist. ... However, his habit of pronouncing on 'new species' with only the help of a hand lens was regarded as rather eccentric". Eccentric he may have been, but his work forms an important part of the present knowledge of European thrips.

\section{Plant Parasite Spreads}

A specres of dodder, the parasitic plant belonging to the Convolvulaceae which grows chiefly on gorse, heather and nettles in Britain, has been found on a vocado trees in Israel. Dr E. Lahov of the Volcani Institute of Agricultural Research in Rehovot, reports that in the summer of 1966 two avocado trees were found to have been attacked by dodder on a plantation in Cabri in western Galilee. The branches which had been attacked were cut and destroyed, but in 1967 thirty trees on the same plantation were found to have been attacked. Cabri is the only place in Israel where dodder has been observed so far. All attacked trees were of the variety 'Ettinger', from seedlings which originated in Israel; other varieties, such as 'Haas' and 'Fuerte', which were growing adjacent to attacked trees, were not affected, which shows that this dodder has a very high specificity.

Professor N. Feinbrun of the department of botany of the Hebrew University of Jerusalem has identified the dodder as Cuscuta cassytoides, Nees von Esenb, a species known only in South Africa. According to the Citrus and Subtropical Research Institute at Nelspruit, South Africa, Cuscuta is known to grow on wild trees next to cultivated avocado trees in the mountainous areas of South Africa when rainfall is high. Professor C. A. Schroeder of the University of California, Los Angeles, has reported that Cuscuta has never been found on avocado trees in California or Florida. Cuscuta is not listed in the Index of Plant Diseases in the United States as occurring on avocado.

This is the first time this species of dodder has been observed in Israel, and it is not known how it was introduced. Young avocado plants or grafts are not known to have been introduced from South Africa. It is, however, possible that other plants served as carriers for the dodder. Nobody yet knows how to check the spread of this dodder, and until further progress is made growers are being recommended to burn the affected avocado branches as soon as the parasite is observed.

\section{Effects of Air Pollution from a Correspondent}

A sYMPOSIC $\mathrm{m}$ on the influence of air pollution on plants and animals, sponsored jointly by the Council of Europe and the Nethcrlands Government, was held at Wageningen from April 22 to 27 . The arrangements were made by an organizing committee, under the chairmanship of Dr J. G. ten Houten, director of the Institute of Phytopathological Research. The symposium. attended by some 150 delegates from 17 countries, was divided into seven sessions. It started with an inventory of damage due to industrial and urban air pollution, then dealt with research, with observations of effects on both wild and domestic plants and animals. with techniques, both mechanical and biological, for measuring pollution, and with the use of vegetation to ameliorate existing conditions. Some 33 papers in English, French and German (with simultaneous translation) were read, and each session finished with a panel discussion.

Those used to British conditions were impressed with the seriousness of the problem in other countries. We have had our own incidents: fluorine damage at Fort William and around brickworks, local high levels of sulphur and smog, "lichen deserts" around our towns, but, by good luck rather than good planning, proved cases of severe damage have been uncommon. In Europe at least 400,000 hectares are severely affected. Thus in Norway conifers may be exterminated for more than $10 \mathrm{~km}$ around aluminium plants. and visible damage extends for three times this distance. In the Netherlands, in areas where horticulture continues next to industrial development, susceptible varieties of crocus, freesia, gladiolus and tulip are seriously affected by fluorine. In Switzerland. both sulphur dioxide and fluorine compounds cause. serious damage. The effects of the photochemical smog in Los Angeles, California, are well known, and are being repeated in other areas in North America with high automobile populations and suitable meteorological conditions. Ozone damage is also serious in the United States. France, Germany, Czechoslovakia. Austria and Yugoslavia have equally serious problems.

Most work has concerned economic damage to vascular plants, though there has been much study of lichens and bryophytes, which may act as "indicator species". Results, however, are not quite clear cut, as microclimates in cities-drier, less dew, higher temperatures -may affect species also susceptible to sulphur. 